The University of Maine

\title{
DigitalCommons@UMaine
}

Earth Science Faculty Scholarship

Earth Sciences

1985

\section{The Glaciochemistry of Snowpits from Quelccaya Ice Cap, Peru, 1982}

W. Berry Lyons

Paul Andrew Mayewski

University of Maine, paul.mayewski@maine.edu

Lonnie G. Thompson

Boyd Allen III

Follow this and additional works at: https://digitalcommons.library.umaine.edu/ers_facpub

Part of the Geochemistry Commons, Glaciology Commons, Hydrology Commons, and the Sedimentology Commons

\section{Repository Citation}

Lyons, W. Berry; Mayewski, Paul Andrew; Thompson, Lonnie G.; and Allen, Boyd III, "The Glaciochemistry of Snowpits from Quelccaya Ice Cap, Peru, 1982" (1985). Earth Science Faculty Scholarship. 204.

https://digitalcommons.library.umaine.edu/ers_facpub/204 


\title{
THE GLACIOCHEMISTRY OF SNOW-PITS FROM QUELCCAYA ICE CAP, PERU, 1982
}

\author{
by \\ W. Berry Lyons and Paul A. Mayewski, \\ (Glacier Research Group, Department of Earth Sciences, University of New Hampshire, Durham, \\ New Hampshire 03824, U.S.A.) \\ Lonnie G. Thompson
}

(Institute of Polar Studies, Ohio State University, Columbus, Ohio 43210, U.S.A.)

and Boyd Allen III

(Glacier Research Group, Department of Earth Sciences, University of New Hampshire, Durham, New Hampshire 03824, U.S.A.)

\begin{abstract}
We present glaciochemical data from a pilot study of two snow-pits from Quelccaya ice cap, Peruvian Andes. These are the first samples to be analyzed from Quelccaya for nitrate and sulfate by ion chromatography (IC), for nitrate-plus-nitrite, reactive silicate and reactive iron by colorimetry, and for sodium by atomic absorption spectrophotometry. The $3 \mathrm{~m}$ pits used in this study represent a one year record of mass accumulation and the 29 samples collected provide the first glaciochemical data from this area which can be compared with glaciochemical studies from other
\end{abstract} locations.

Reactive iron, reactive silicate and sodium, and the profiles of $>0.63 \mu \mathrm{m}$ microparticles from Thompson and others (1984) are coincident, suggesting that transport and deposition into this area of each species are controlled by similar processes. The common source is probably local, resulting from crustal weathering. In general, the reactive silicate values are lower than those observed in other alpine glacier ice. The highest sulfate and nitrate values were observed in the upper few centimeters of the snow-pit. Most of the sulfate concentrations were less than $3 \mu \mathrm{M}$ and are similar to values obtained for fresh surface snows from Bolivia (Stallard and Edmond 1981). Since biological gaseous emissions are thought to be the major source of sulfur and nitrogen to the atmosphere over the Amazon basin, the sulfate and nitrate fluctuations may be due to seasonal biological input and/or seasonal shifts in wind direction bringing material to Quelccaya.

With only one exception, the colorimetric nitrate-plus-nitrite data were higher than the IC nitrate data. Unfortunately, the IC analyses were conducted 81 $d$ after the colorimetric analyses. The difference between the two data sets could be attributable to the following: (1) the colorimetric technique may yield erroneously high results as suggested for polar ice by Herron (1982), (2) the IC technique yields erroneously low results due, in part, to the possible exclusion of nitrite concentrations, and/or (3) nitrite was lost via biological removal during the $81 \mathrm{~d}$ period before the IC analyses. If the IC data are correct, the mean nitrate value is $0.4 \mu \mathrm{M}(\mathrm{n}=29)$. This value is similar to those reported from pre-industrial aged polar ice (Herron 1982). If the colorimetric mean value $(1.1 \mu \mathrm{M})$ is correct, it is similar to colorimetrically determined values from other high-elevation alpine ice (Lyons and Mayewski 1983).

\section{INTRODUCTION}

The chemistry of polar ice and snow has long been employed as a paleo-atmospheric surrogate (Murozumi and others 1969, Herron 1982, Boutron and Patterson 1983). Only recently have studies of high-altitude temperate and tropical alpine glaciers been undertaken to determine if these types of permanent ice/snow fields provide detailed records of past atmospheric conditions (Lyons and Mayewski 1983, Haeberli and others 1983, Thompson and others 1984, Mayewski and others 1984). We present glaciochemical data from samples collected in two 3-m snow pits from Quelccaya ice cap, Peru. Although these samples represent only one year of precipitation accumulation, these are the first glaciochemical data from a South American ice field. These data suggest that chemical records reflecting changes in atmospheric chemistry, and therefore atmospheric circulation and climate dynamics, may be retrieved from certain high-elevation glaciers. Such glaciers must experience the physical environment and local climatic conditions essential to the preservation of annual stratigraphic and geochemical records.

The Quelccaya ice cap $(5670 \mathrm{~m})$ and the summit sampling location, along with complementary studies on its modern climate, have been discussed in detail previously (Hastenrath 1978, Thompson and others 1979, 1984. Thompson 1980, Mosley-Thompson 1982). Therefore this information will not be repeated here.

\section{METHODOLOGY}

Samples were collected in July 1982, using pre-cleaned plexiglass scrapers and distilled-deionized washed polyethylene bottles $(30 \mathrm{ml})$, and immediately inserted into polyethylene bags. Groups of bagged bottles were then placed in another plastic bag for transport Personnel wore polyethylene gloves and particle masks.

Sodium was analyzed by flame atomic absorption spectrometry using a Perkin-Elmer model 2280. Cesium chloride solution was added to the $2 \mathrm{ml}$ sample for a final concentration of $2 \%$ to control ionization. Reactive silicate was determined colorimetrically using $5 \mathrm{ml}$ samples on an AutoAnalyzer II (Glibert and Loder 1977) while reactive iron was analyzed colorimetrically (Stookey 1970) using low-volume $10 \mathrm{~cm}$ cells. For the iron analysis $5 \mathrm{ml}$ aliquots were added to acid-washed test tubes containing $0.03 \mathrm{ml}$ reducing agent, $0.20 \mathrm{ml}$ Ferrozine solution and $0.25 \mathrm{ml}$ buffer solution. Reactive silicate and reactive iron are defined as the amount of silicate and iron reacting colorimetrically after an addition of Baker Ultrex nitric acid (Mayewski and Lyons 1982). The above analyses were made in the laboratories of the Department of Earth Sciences at the University of New Hampshire.

Sulfate and nitrate were determined simultaneously on a Dionex 10 ion chromatograph (IC) at $0.3 \mu \mathrm{S}$ 
conductivity using an anion separation column with an elution time of $7.5 \mathrm{~m}$, the eluent consisting of $0.003 \mathrm{~mol}$ $\mathrm{NaHCO}_{3}$ and $0.002 \mathrm{~mol} \mathrm{Na}_{2} \mathrm{CO}_{3}$. Samples were injected with a Hamilton Teflon tipped gas-tight syringe into a 1 $\mathrm{ml}$ loop. The analysis was performed in the Class 100 clean laboratory at the Mellon Institute, Pittsburgh, Pennsylvania. In addition, nitrate-plus-nitrite was analyzed in an AutoAnalyzer II (Glibert and Loder 1977).

Analytical error $\left(\begin{array}{llll} \pm & 1 & \text { standard deviation }) \text { was }\end{array}\right.$ estimated from the standard deviation in replicate runs of standards and samples. These are listed in Table I. Bottle blanks were created by filling washed sample bottles with Milli-Q in the laboratory. These bottles were then processed as samples and underwent identical handling and analytical procedures. Blank concentration means are also listed in Table I.

TABLE I. ANALYTICAL ERRORS, LISTED FOR STANDARDS, SAMPLES AND BLANKS

Analytical error $(\boldsymbol{\mu M})$

\begin{tabular}{|c|c|c|}
\hline Standards & Samples & Blanks \\
\hline 0.03 & 0.09 & 0.13 \\
\hline 0.02 & 0.03 & 0.04 \\
\hline 0.001 & 0.01 & 0.02 \\
\hline 0.02 & 0.04 & 0.06 \\
\hline 0.01 & 0.01 & 0.01 \\
\hline 0.03 & - & 0.03 \\
\hline
\end{tabular}

\section{RESULTS AND DISCUSSION}

Glaciochemical results are plotted with depth in Figures 1 and 2. Only reactive silicate, reactive iron, and sodium were measured in both pits; therefore we will only discuss the results of pit $\#$ in detail. As mentioned above, although these data only represent a year's accumulation, some general statements can be made regarding chemical distribution with depth and its relationship with climatic events.

Reactive silicate, reactive iron, and sodium profiles are similar to that of the $>0.63 \mu \mathrm{m}$ microparticle profile in both pits (e.g. compare Figure 1 in this paper with figure 3 from Thompson and others 1984). Therefore we assume that these three chemical species have a common primary source from crustal weathering. This deposition is at a maximum during the dry austral winter (Thompson and others 1979, 1984), due to a combination of (1) a dominant wind direction from the west and north-west, transporting material from the high, dry Altiplano, (2) slightly higher mean wind speeds during this season, and (3) the seasonal difference in snow mass accumulation. Thus we suggest that higher concentrations of crustal material are deposited during the dry season when they are not diluted by snow accumulation. This seasonal microparticle (and one would expect reactive silicate, reactive iron and sodium) signal is preserved on Quelccaya to bedrock (Thompson and others 1984). During the dry, more windy season, the predominant wind is from the west and north-west, so some of the sodium deposited at this time may be marine in origin.

If the six values $>1 \mu M$ for reactive silicate and the six values $>2 \mu M$ for reactive iron are included, the mean values from snow pit $1(\mathrm{n}=29)$ are 1.71 and $1.79 \mu \mathrm{M}$, respectively. The six highest reactive silicate and iron values are coincident and represent June to July in 1981 and 1982, again indicating that the highest concentrations of these chemical species are deposited during the dry season when the microparticle
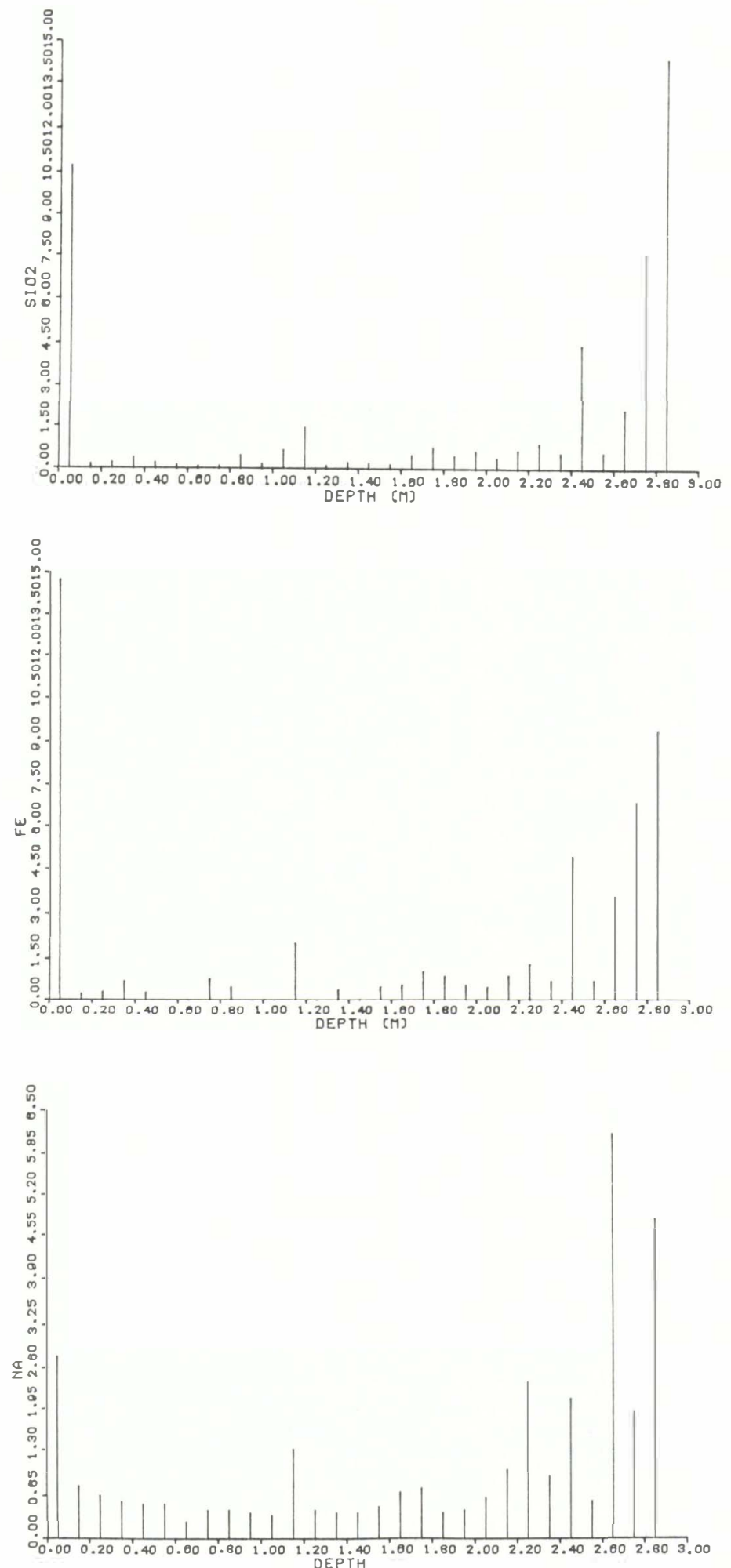

Fig. 1. Concentrations in $\mu \mathrm{M}$ of reactive silicate, reactive iron and sodium ( $\boldsymbol{\mu M})$ plotted against depth $(\mathrm{m})$ in snow-pit 1 , Quelccaya ice cap.

concentrations are also the highest. If those six samples are disregarded, the means decrease dramatically to 0.39 and $0.46 \mu \mathrm{M}$, respectively. Stallard and Edmond (1981) reported values of $0.3 \mu \mathrm{M}$ (austral summer) and $0.6 \mu \mathrm{M}$ (austral winter) for surface snows at Chacaltaya Observatory, Bolivia $(5222 \mathrm{~m})$. These sparse data from the Bolivian Andes suggest higher crustal debris accumulation during the dry winter season. The values are lower than those observed by us for other alpine glaciers (Butler and others 1980, Mayewski and Lyons 1982, Mayewski and others 1984), indicating that Quelccaya ice cap receives less crustal weathering 

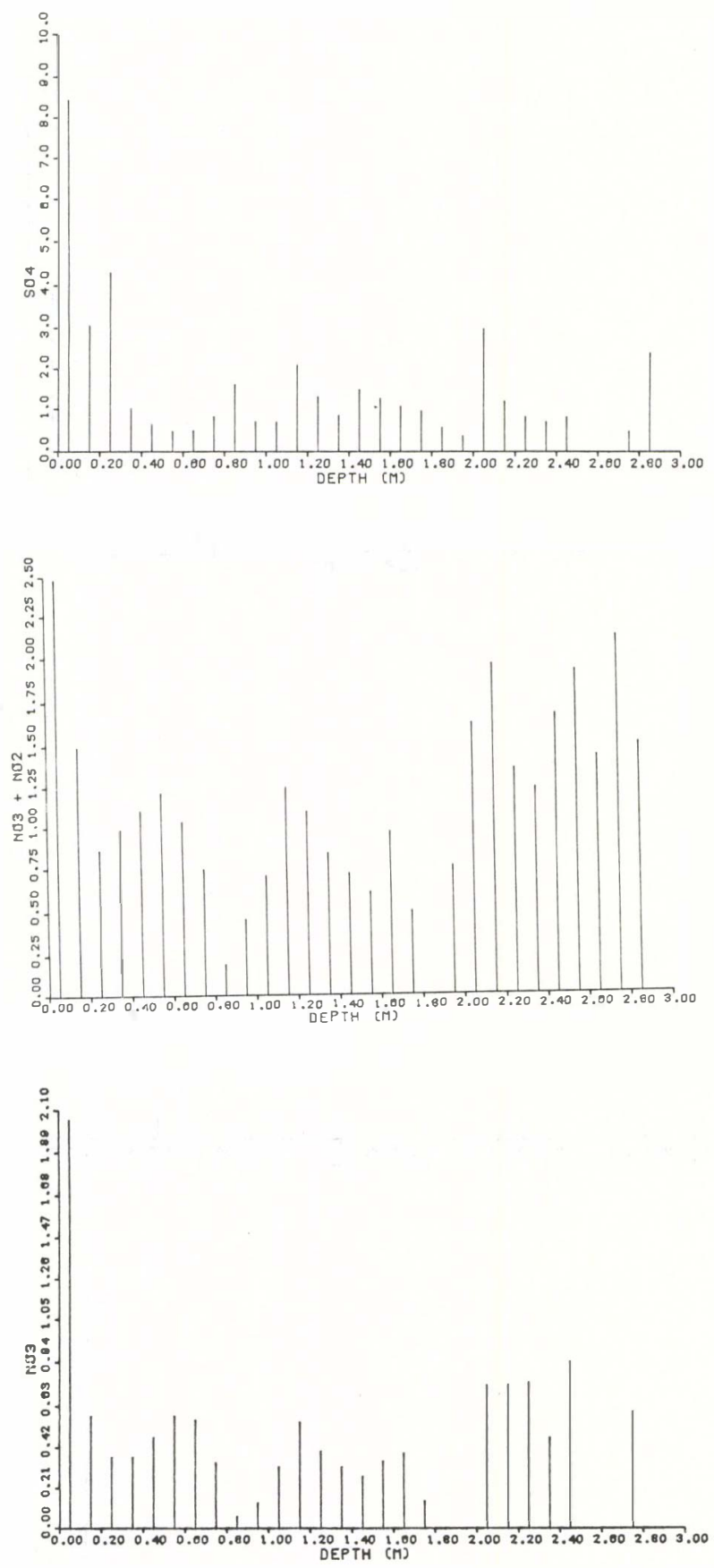

Fig. 2. Concentrations in $\mu \mathrm{M}$ of sulfate, nitrate-plus-nitrite and nitrate plotted against depth in snow-pit $\#$, Quelccaya ice cap.

material than these other glaciers. The unity of the $\mathrm{Si} / \mathrm{Fe}$ ratios $(\sim 1: 1)$ throughout the year in the pit (Fig.1) suggests that the material is from the same source and that these crustal materials may be of local origin.

The highest sulfate, nitrate, and nitrate-plus-nitrite values are also in the top few centimeters of the snow-pit (Fig.2). Nitrate and nitrate-plus-nitrite concentrations also appear to increase toward the bottom of the snow-pit. These profiles are similar to those of the crustally derived species. This may reflect the seasonal difference in wind direction (from west to north-west in the dry season as opposed to east to south-east during the wet season) responsible for the variation in the nitrogen data. However, unlike nitrate, sulfate shows no increase at depths from 2.0 or $2.2 \mathrm{~m}$ to $2.8 \mathrm{~m}$, indicating that the influx of sulfate into the area is different to the other chemical species under investigation.

Recent studies have indicated that tropical rain forests of the Amazon basin are a major source of atmospheric nitrogen and sulfur (Lawson and Winchester 1979, Stallard and Edmond 1981). A variation in this biogenic source term may therefore alter the concentrations of both nitrogen and sulfur in the Quelccaya precipitation. The time and amount of clear cutting and burning of tropical forest may also affect the nitrogen and sulfur precipitation chemistry in this area (Galloway and others 1982).

The sulfate values obtained in this study are low $(<3 \mu \mathrm{M})$ but are higher than those reported for polar snow (Herron 1982). They compare well with those of Stallard and Edmond (1981) for Bolivian snows (2.1 to $3.2 \mu \mathrm{M})$ and also are within the range of the mean precipitation values of $5.1 \mu \mathrm{M}$ for the Amazon basin (Stallard and Edmond 1981) and of $1.6 \mu \mathrm{M}$ for the Venezuelean Amazonas (Galloway and others 1982). These data indicate, at least in a preliminary sense, that in areas to the north and west of the Amazon basin, sulfate concentrations in precipitation appear to have similar mean values, indicating the influence of the basin as a source. The mean precipitation values from nitrate for the Amazon basin is $2.1 \mu \mathrm{M}$ (Stallard and Edmond 1981) and for the Venezuelean Amazonas 3.5 $\mu \mathrm{M}$ (Galloway and others 1982). Stallard and Edmond (1981) analyzed one fresh snow sample from the Bolivian Andes and obtained a concentration of nitrate of $3.4 \mu \mathrm{M}$. Both these groups of investigators employed the cadmium reduction colorimetric technique.

The IC nitrate data in all but one case for the Quelccaya data were lower than the colorimetrically determined nitrate-plus-nitrite values (Fig.2). Based on the precision of these analyses (Table I) this discrepancy is real. Obviously this is not a trivial problem. Most of the previous precipitation data have been analyzed for nitrate by the colorimetric technique. Recently more laboratories have switched to IC instrumentation and thus it is critical to determine if data sets generated by the two techniques are compatible. Unfortunately the IC analyses were undertaken $81 \mathrm{~d}$ after the nitrate-plus-nitrite analyses. The samples arrived at the

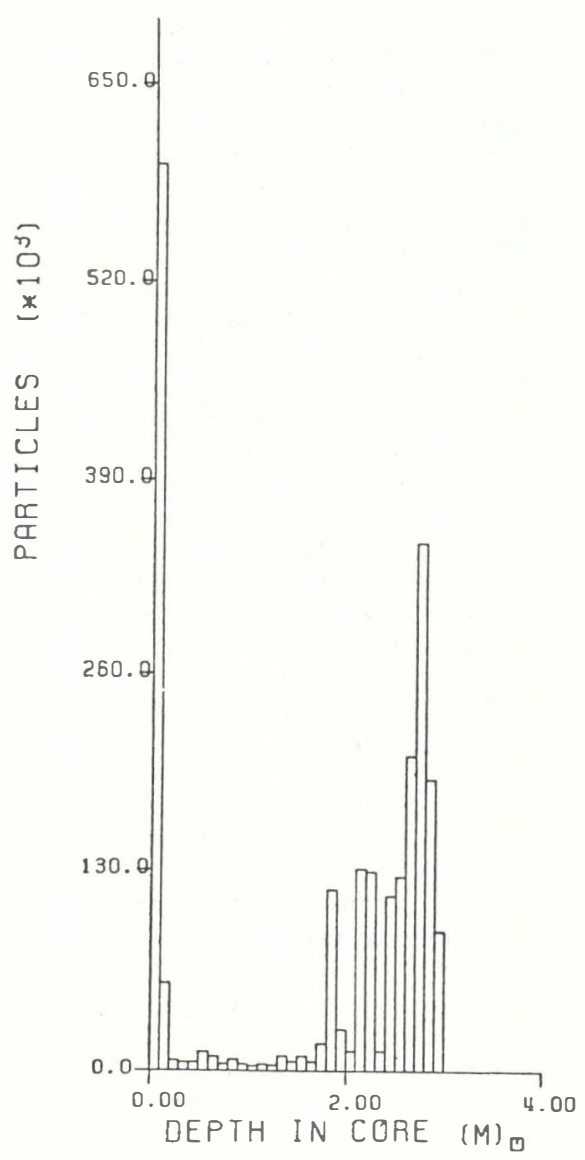

Fig. 3. Microparticle data $(>0.63 \mu \mathrm{m})$ plotted against depth in snow-pit 1 , Quelccaya ice cap. 
laboratory in an unfrozen state and were immediately frozen $\left(-20^{\circ} \mathrm{C}\right)$. Upon thawing, the nitrate-plus-nitrite analysis was the first to be undertaken. After this analysis was completed, the samples were again refrozen and finally thawed again and analyzed $81 \mathrm{~d}$ later for nitrate by means of IC. The difference between the two data sets could be due to one of three possibilities: (1) the colorimetric techniques yield erroneously high results, or (2) the IC technique yields erroneously low results, or (3) loss of nitrate occurs during the interval between the two different analyses. Herron (1982) has suggested that his observed differences between nitrate data from Dye 3, Greenland and South Pole, Antarctica and those of other investigators reflect real differences between these two analytical techniques. Using ion chromatography, Herron's data were consistently lower than the other studies which used cadmium reduction colorimetry. It is possible that either the colorimetric technique, as suggested by Herron (1982), yields higher than "true" values, or that the IC techniques yield lower than "true" values for nitrate.

During IC runs nitrite standards were not analyzed. On a limited number of IC samples a small peak, probably nitrite, was observed, but in most cases this peak was obscured by the much larger chloride peak. Harding and Miller (1982), employing IC instrumentation, have analyzed precipitation samples from Hawaii for both nitrate and nitrite. The concentrations were similar. To our knowledge these are the first data indicating that nitrite is an important component of tropical/subtropical precipitation. It is tempting to interpret the difference between the one IC and colorimetric data as nitrite. However, without collaborative IC nitrite data we can only speculate that this is, indeed, the case. In addition, very little to no nitrate has been observed in polar ice ( $M$ Herron and $R$ Delmas personal communication).

On the other hand, the discrepancy between the data sets may not be due to analytical problems alone. Two lines of evidence argue against this: (1) Risbo and others (1981) have published nitrate-plus-nitrite values from Greenland, using the cadmium reduction colorimetric technique, which are similar to Herron's (1982) IC values, and (2) Pyen and Fishman (1979) have analyzed diluted marine pore waters by both techniques (Dionex IC and automated cadmium reduction colorimetry) and found general agreement between the two with no evidence that the colorimetric method gave constantly higher results. If our colorimetric values are zorrect, the mean is similar to that observed in other lpine glacier ice/snow from remote areas, that is, $\sim 1$ $\mu \mathrm{M}$ (e.g. Lyons and Mayewski 1983).

The lower IC values (mean $\sim 0.4 \mu \mathrm{M}$ ) may reflect the loss of nitrate during the $81 \mathrm{~d}$ period after the initial colorimetric measurements. Either a biologica removal or adsorption processes within the thawed samples may have led to the removal of nitrate and the colorimetric data may resemble more closely natural concentrations of these chemical species in Quelccaya snow. Much has been written about the preservation of natural water samples for chemical analysis, but it is not appropriate to review that literature in any detail here. Some information does exist, however, on the preservation of samples with very low nitrate concentrations. Legrand and others (1984) discuss the possible increase of nitrate and nitrite with time due to atmospheric gas contamination of ice samples. No nention is made of possible nitrate loss.

Morse and others (1982) have recently shown that surface water ocean samples of low nitrate concentration ( $0.3 \mu \mathrm{M}$ and less) could not be stored without some loss of nitrate, whatever method of preservation (even freezing) was employed). At the much higher concentrations of ocean deep waters $(\sim 20 \mu \mathrm{M})$ nitrate loss was not a problem as long as the samples were kept in a cool dark place and stored in polyethylene containers. Galloway and Likens (1976) have argued that precipitation samples could be stored for seven months at temperatures as high as $21^{\circ} \mathrm{C}$ without negligible nitrate loss or gain. However, the nitrate values in their precipitation was approximately 32 times higher than our mean colorimetric value for Quelccaya.

\section{CONCLUSIONS}

The major conclusions of this study are as follows:

(1) reactive silicate, reactive iron and sodium profiles are coincident with the $>0.63 \quad \mu m$ microparticle profiles indicating a common source of weathered crustal material,

(2) the above-mentioned chemical species reach their highest concentrations in the dry season (the austral winter) indicating dependency on wind direction and/or snow accumulation rate,

(3) nitrate and sulfate concentrations in the Quelccaya snow-pit are highest near the surface and are similar to those reported for precipitation around the Amazon basin,

(4) the source of the $\mathrm{N}$ and $\mathrm{S}$ in Quelccaya precipitation may be primarily biogenic input from the Amazon basin,

(5) nitrate values determined by ion chromatography are lower than nitrate-plus-nitrite values determined by automated colorimetry; whether this is an analytical artefact or a problem of sample handling is unknown at present, and

(6) further glaciochemical studies on the Quelccaya ice cap may provide an important paleoclimatic record.

\section{ACKNOWLEDGEMENTS}

We are extremely grateful to Dr C I Davidson at Carnegie-Mellon University and $\mathrm{Dr} T \mathrm{C}$ Loder at the University of New Hampshire for the use of their analytical facilities. We thank $\mathrm{Dr} M \mathrm{~J}$ Spencer and $\mathrm{Mr} J$ Love for valuable discussion regarding the nitrate problem.

\section{REFERENCES}

Boutron C F, Patterson C C 1983 The occurrence of lead in Antarctic recent snow, firn deposited over the last two centuries and prehistoric ice. Geochimica et Cosmochimica Acta 47(8): 1355-1368

Butler D, Lyons W B, Hassinger J, Mayewski P A 1980 Shallow core snow chemistry of Athabasca Glacier, Alberta. Canadian Journal of Earth Sciences 17(2): $278-281$

Galloway J N, Likens G E 1976 Calibration of collection procedures for the determination of precipitation chemistry. Water, Air and Soil Pollution 6: 241-258

Galloway J N, Likens G E, Keene W C, Miller J M 1982 The composition of precipitation in remote areas of the world. Journal of Geophysical Research 87(C11): 8771-8786 Glibert P M, Loder T C 1977 Automated analysis of nutrients in seawater: a manual of techniques. Woods Hole Oceanographic Institute. Technical Report 77-47

Haeberli W, Schotterer U, Wagenbach D, Haeberli-Schwitter H, Bortenschlager S 1983 Accumulation characteristics on a cold, high-Alpine firn saddle from a snow pit study on Colle Gnifetti, Monte Rosa, Swiss Alps. Journal of Glaciology 29(102): 260-271

Harding D, Miller J M 1982 The influence on rain chemistry of the Hawaiian volcano Kilauea. Journal of Geophysical Research 87(C2): 1225-1230

Hastenrath S 1978 Heat-budget measurements on the Quelccaya ice cap, Peruvian Andes. Journal of Glaciology 20(82): 85-97

Herron M M 1982 Impurity sources of $\mathrm{F}^{-}, \mathrm{Cl}^{-}, \mathrm{NO}_{3}^{-}$and $\mathrm{SO}_{4}{ }^{2-}$ in Greenland and Antarctic precipitation. Journal of Geophysical Research 87(C4): 3052-3060

Lawson D R, Winchester J W 1979 Sulfur, potassium, and phosphorus associations in aerosols from South American tropical rain forests. Journal of Geophysical Research 84(C7): 3723-3727

Legrand M, De Angelis M, Delmas R J 1984 Ion chromatographic determination of common ions at ultratrace levels in Antarctic snow and ice. Analytica Chimica Acta 156: 181-192

Lyons W B, Mayewski P A 1983 Nitrate plus nitrite concentrations in a Himalayan ice core. Geophysical Research Lellers 10(12): 1160-1163 
Mayewski P A, Lyons W B 1982 Source and climatic implication of the reactive iron and reactive silicate concentration found in a core from Meserve Glacier, Antarctica. Geophysical Research Letters 9(3): 190-192

Mayewski P A, Lyons W B, Ahmad N, Smith G, Pourchet M 1984 Interpretation of the chemical and physical time-series retrieved from Sentik Glacier, Ladakh Himalaya, India. Journal of Glaciology 30(104): 66-76

Morse J W, Hunt M, Zullig J, Mucci A, Mendez T 1982 A comparison of techniques for preserving dissolved nutrients in open seawater samples. Ocean Science and Engineering 7: 75-106

Mosley-Thompson E 1982 Analysis of the Quelccaya ice cap climate record. Progress report. Columbus, $\mathrm{OH}$, Ohio State University, Institute of Polar Studies.

Murozumi M, Chow T J, Patterson C C 1969 Chemical concentrations of pollutant lead aerosols, terrestrial dusts and sea salts in Greenland and Antarctic snow strata. Geochimica et Cosmochimica Acta 33(10): 1247-1294

Pyen G S, Fishman M J 1979 Determination of anions in pore waters from cores by ion chromatography. In Sawicki E, Mulik J D (eds) Ion chromatographic analysis of environmental pollutants. Vol 2. Ann Arbor, MI, Ann Arbor Science Publishers: 235-244

Risbo T, Clausen H B, Rasmussen K L 1981 Supernovae and nitrate in the Greenland ice sheet. Nature 294(5842): 637-639

Stallard R F, Edmond J M 1981 Geochemistry of the Amazon. 1. Precipitation chemistry and the marine contribution to the dissolved load at the time of peak discharge. Journal of Geophysical Research 86(C10): 9844-9858

Stookey L L 1970 Ferrozine - a new spectrophotometric reagent for iron. Analytical Chemistry 42(7): 779-781

Thompson L G 1980 Glaciological investigations of the tropical Quelccaya ice cap, Peru. Journal of Glaciology 25(91): 69-84

Thompson L G, Hastenrath S, Morales Arnao B 1979 Climatic ice core records from the tropical Quelccaya ice cap. Science 203(4386): 1240-1243

Thompson L G, Mosley-Thompson E, Grootes P M, Pourchet M, Hastenrath S 1984 Tropical glaciers: potential for ice core paleoclimatic reconstructions. Journal of Geophysical Research 89(D3): 4638-4646 